\title{
Characterization of the Spindle Morphology Nanomicelles Assembled from Sericin and Gelatin
}

\author{
Xiaozhou Su, ${ }^{1}$ Lei $\mathrm{Li}^{2}{ }^{2}$ and Weihan Huang ${ }^{1}$ \\ ${ }^{1}$ School of Textiles, Zhongyuan University of Technology, Zhengzhou 450007, China \\ ${ }^{2}$ School of Civil and Architecture Engineering, Zhengzhou University of Aeronautics, Zhengzhou 450015, China
}

Correspondence should be addressed to Xiaozhou Su; 739853899@qq.com

Received 29 June 2017; Revised 24 September 2017; Accepted 10 October 2017; Published 14 November 2017

Academic Editor: Felipe A. La Porta

Copyright (C) 2017 Xiaozhou Su et al. This is an open access article distributed under the Creative Commons Attribution License, which permits unrestricted use, distribution, and reproduction in any medium, provided the original work is properly cited.

Complex nanomicelles were prepared by sericin and type A gelatin with molecular weight of $5789 \mathrm{Da}$ and $128664 \mathrm{Da}$ separately. The assembling conditions were as follows: mass ratio (sericin/gelatin) was $1: 1$, protein concentration was $0.5 \%$, temperature was $35^{\circ} \mathrm{C}$, and assembling time was 18 hours. Scanning electron microscopy (SEM), atomic force microscopy (AFM), transmission electron microscopy (TEM), Fourier transform infrared (FT-IR) spectroscopy, differential scanning calorimetry (DSC), and dynamic light scattering (DLS) were conducted to observe and characterize the complex nanomicelles. Results showed that the complex sericin/gelatin micelles was a kind of nanospindle micelles. The micelles had high electrochemical stability, thermal stability, antidilution stability, and storage stability.

\section{Introduction}

Amphiphilic block copolymer included synthetic polymers and natural polymers. Natural polymers included casein, keratin, gelatin, collagen, silk fibroin, and sericin. Due to the safety, nontoxicity, stable performance, good biocompatibility, and low price for the natural polymer, it had received more and more attention in recent years.

The phase behavior of the synthetic block polymer for diblock copolymers (A-B) and triblock copolymers (A-B-A, $A-B-C)$ had been extensively investigated [1-3]. It included PB-PDMS, PE-PEE, PS-PI, PI-PS, PEO-PEE PI-PS-P2VP, PS-PEB-PMMA, PS-PI-P2VP, PS-PB-P2VP, and PI-PS-PI; it can self-organize into spherical, cylindrical, lamellar, gyroid morphologies, and so on [4-13].

Complex micelles were different from ordinary polymeric micelles. Complex micelles core or shell was composed of two or more than two kinds of polymers (or polymers with small molecular compounds) by ionic bonding, hydrogen bonding, van der Waals force, and other intermolecular forces. The introduction of multicomponent provided complex micelles with more excellent properties and also increased the regulation performance [14-20]. Organic/organic, organic/metal, inorganic/organic, and biological/abiotic composites and nanocomposites with more sophisticated structure can be acquired by self-assembling of the complex micelles. The diversity of these materials through self-assembling far more exceeded other methods. These versatile and unique selfassembly materials will be widely used in many fields, such as optoelectronics, biopharmaceuticals, and chemical engineering [21, 22].

Protein was an atypical block copolymer. The assembling principle for protein micelles in solution was more complex. Not only can protein chain segment, temperature, time, and $\mathrm{pH}$ affect the assembling process, but also the multilevel structure of protein can have significant influence. Research showed that some protein can be assembled into spherical micelles [23-27]. But there were seldom reports on assembling different morphology of complex micelles based on using different proteins by controlling assembling conditions.

Based on these viewpoints, our studies intended for specific morphology and performances have been conducted. There were numerous potential exciting discoveries and applications of these complex block copolymer morphologies that currently awaited exploitation. New materials with exceptional property can be prepared through 
self-assembling by using natural protein. This material belonged to double hydrophilic aqueous block copolymer and it can respond to any changes in environmental conditions in aqueous solution. This kind of environment was similar to the microenvironment in which organisms and cell existed. Therefore, this type of polymer will play an important role in the field of drug release, cell simulation, biosensor, and virus detection [28-30]. Micelles with different morphology had diverse applications in drug delivery. For example, rod-like micelles had different drug loading space and drug release kinetics compared with the spherical micelles. Rod-like micelles had significant advantages over spherical micelles in preparing pulmonary delivery system because of thin wall structure [31].

Sericin was a kind of natural material that had long been taken as waste in silk reeling industry. It has many bioactivities, such as moisturizing, antibacterial, antioxidant, anti-inflammatory, and anticancer functions. It can promote cell adhesion and proliferation and has good biocompatibility and low immunogenicity. It owned a large number of chemical groups such as amino, hydroxy, and carboxyl group that can be used for chemical crosslinking and modification [3237]. Gelatin was derived from collagen and it had excellent biocompatibility and biodegradability. It also had massive functional groups in amino acid side chains which can be easily modified and cross-linked. In recent years, gelatin had been widely used in drug delivery system [38-41]. Based on these characteristics, our experiment intended for acquiring complex micelles with specific morphology and property had been conducted by using sericin and gelatin. The product can be used for cosmetic and food, drug release, biosensor and nanomaterial processing, and manufacturing.

\section{Materials and Methods}

2.1. Materials. Porcine skin type A gelatin (V900863, reagent grade) was supplied by Sigma Company Ltd. Sodium carbonate was used to dissolve the sericin protein. The reaction temperature was $95^{\circ} \mathrm{C}$, system $\mathrm{pH}$ was 13 , mass concentration of sodium carbonate was $5 \mathrm{~g} / \mathrm{L}$, liquor ratio was $50: 1$, and the reaction time was 3 hours. All the other reagents used were of analytical grade. The ultrafiltration membrane with molecular weight cutoff $500 \mathrm{Da}$ was used to purify the sericin.

2.2. Molecular Weight Measurement. Sericin protein and gelatin solutions with $2 \%$ mass concentration were prepared with $0.1 \mathrm{M} \mathrm{NaNO}_{3}$ buffer. The measurement was performed at the high performance liquid chromatograph (Waters, 600E2487). 0.1 $\mathrm{M}$ of $\mathrm{NaNO}_{3}$ buffer was used as mobile phase and glucan as standard sample.

2.3. Preparation of the Complex Micelles. The method used by Liu et al. served as reference method in preparation complex micelles $[23,24]$. Sericin and gelatin solutions with $0.5 \%$ mass concentration were prepared individually. These two types of solutions were mixed together at the mass ratio of $1: 1$; then the $\mathrm{pH}$ of the mixed solution was adjust to 6.5 and assembled at $35^{\circ} \mathrm{C}$ for 18 hours. Finally, $2.5 \%$ glutaraldehyde solution was added to fix the complex micelle at $25^{\circ} \mathrm{C}$ for at least 12 hours.

2.4. Assembly Efficiency Measurement. The assembly efficiency was measured by ortho-phthalaldehyde (OPA) method. The method of preparing OPA solution is based on the protocol report by Goodno et al. [42]. $80 \mathrm{mg}$ of ortho-phthalaldehyde was added to $2 \mathrm{~mL} \mathrm{95 \%} \mathrm{ethanol} \mathrm{and} 50 \mathrm{~mL} 0.1 \mathrm{~mol} / \mathrm{L}$ $\mathrm{Na}_{2} \mathrm{~B}_{4} \mathrm{O}_{7}$ solution ( $\mathrm{pH}$ 9.5) was prepared firstly. These two solutions were then transferred to a $100 \mathrm{~mL}$ volumetric flask, added to $10 \mathrm{~mL} 10 \%$ SDS solution and $0.2 \mathrm{~mL}$ mercaptoethanol, and diluted with deionized water to $100 \mathrm{~mL} .0 .1 \mathrm{~mL}$ sericin/gelatin mixed solution $(0.5 \%)$ and complex micelles solution $(0.5 \%)$ with different weight ratios were mixed with $2.7 \mathrm{~mL}$ OPA solution and their absorbance at $340 \mathrm{~nm}$ was measured by UV/VIS spectrometer. L-leucine was used as standard sample and its working curve was obtained at the same test conditions. The formula for calculating assembly efficiency is as follows: assembly efficiency $(\%)=(1-$ $\left.A_{r} / A_{0}\right) \times 100 \%$, where $A_{0}$ was the absorbance of the solution before assembly and $A_{r}$ was the absorbance of the solution after assembly.

2.5. Dynamic Light Scattering and Zeta-Potential Measurement. The apparent $z$-average diameter $\left(D_{h}\right)$, polydispersity (PDI), and zeta-potential were measured by a Zeta Sizer Nano ZS90 (Malvern Instrument, Worcs, UK) equipped with $4 \mathrm{~mW}$ $\mathrm{He}-\mathrm{Ne}$ Laser. The test was carried out at $25.0 \pm 0.1^{\circ} \mathrm{C}$, and the measurements were performed at a scattering angle of $90^{\circ}$. The concentration was $0.5 \mathrm{mg} / \mathrm{mL}$ for measurement in each micelles sample.

2.6. Scanning Electron Microscopy (SEM) Measurements. The morphology of the micelles was observed by Hitachi S4800 field emission scanning electron microscope at $1 \mathrm{kV}$ by using the liquid nitrogen. The micelle solution $(0.5 \%)$ was diluted 500 times and dried at the room temperature. The specimens were coated with gold and conditioned at $23 \pm 2^{\circ} \mathrm{C}$ in desiccators containing saturated solutions of $\mathrm{Mg}\left(\mathrm{NO}_{3}\right)_{2} \cdot 6 \mathrm{H}_{2} \mathrm{O}(50 \pm 2 \%$ relative humidity, $\mathrm{RH})$ for at least $12 \mathrm{hs}$ prior to testing.

2.7. Atomic Force Microscopy (AFM) Measurements. Micelle samples were prepared by dropping the solution on silicon surface and dried at room temperature. The test was carried out on Seiko Atomic Force Microscopy SPA400-SPI3800N in tapping mode.

2.8. Transmission Electron Microscopy (TEM) Measurements. TEM characterization was performed on a FEI Tecnai F20 TEM using the Nanofactory TEM-scanning tunneling microscopy (STM) holder. The micelles concentration was $0.5 \mathrm{mg} / \mathrm{mL}$ for testing.

2.9. Fourier Transform Infrared (FT-IR) Spectroscopy Analysis. FT-IR spectra of the complex micelles were measured by an Equinox 55 Spectrometer (Bruker). The sample was 


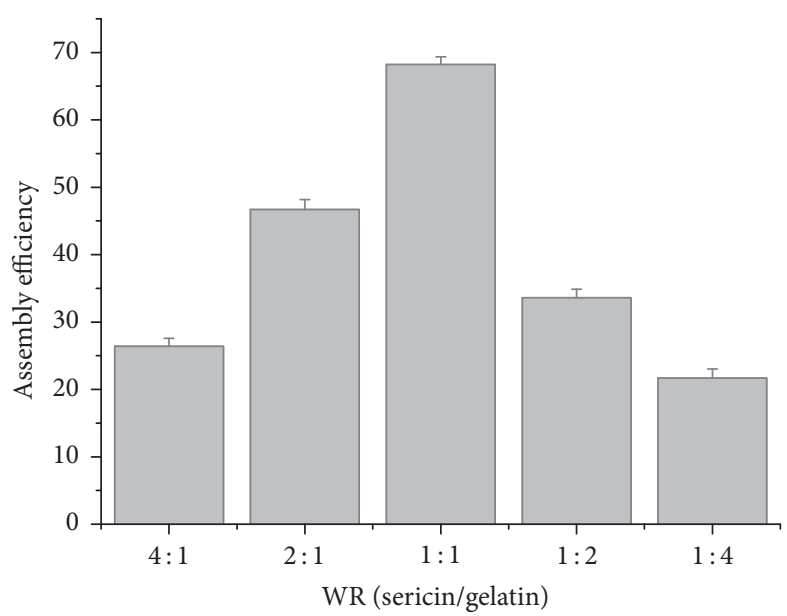

FIGURE 1: Assembly efficiency of the sericin/gelatin complex micelles prepared on the different weight ratio (WR).

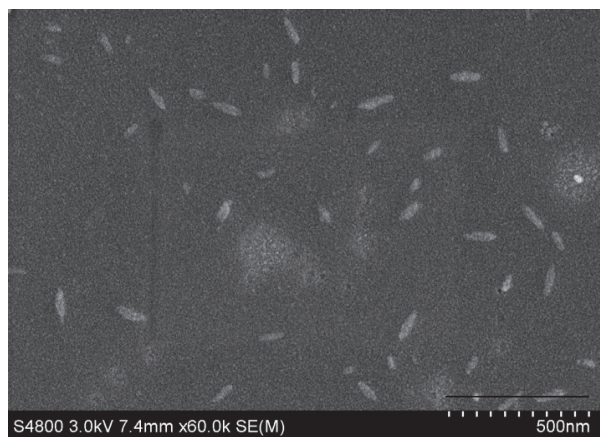

(a)

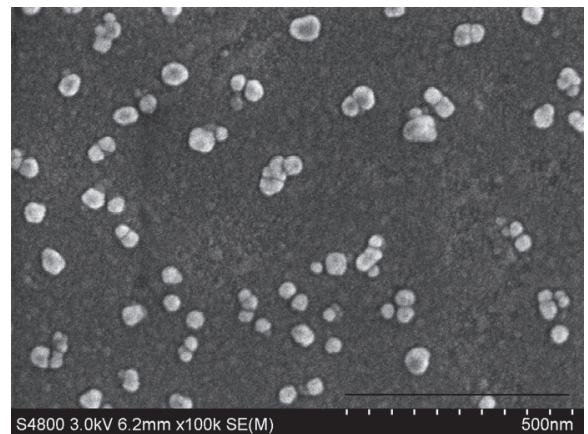

(b)

FIGURE 2: SEM images of the sericin/gelatin nanomicelles (a) and sericin micelles (b). The micelles were diluted 500-fold.

desiccated in vacuum freeze dryer for $12 \mathrm{hs}$ before test. The analysis was performed in triplicate.

2.10. Thermal Analysis. Differential scanning calorimetry (DSC) measurements were performed with an instrument (TA DSC-Q2000) from $40^{\circ} \mathrm{C}$ to $350^{\circ} \mathrm{C}$ at a heating rate of $5^{\circ} \mathrm{C} / \mathrm{min}$. The sample was desiccated in vacuum freeze dryer for $12 \mathrm{hs}$ to get rid of the moisture before testing.

\section{Results and Discussion}

3.1. Assembly Efficiency of the Complex Micelles. Absorbance $A$ was used to perform linear fitting calculation with concentration $C$. The standard curve equation is as follows: $A=$ $0.0814 C+0.01744, R^{2}=0.9995$. It showed a good linear relationship for L-leucine between $A$ and $C$ when its concentration is in the range of $50-800 \mu \mathrm{g} / \mathrm{mL}$. The absorbance was measured under different ratio of weight $(4: 1,2: 1,1: 1$, $1: 2,1: 4)$ for sericin/gelatin before and after preparation of the complex micelles. The results of the assembly efficiency were shown in Figure 1. As the figure showed, the assembly efficiency was different with the different WR value for sericin/gelatin, and it had the maximum value of $68.2 \%$ when the weight ratio of sericin to gelatin is at $1: 1$. As a consequence, subsequent studies will be carried out based on the complex micelles prepared on the WR of sericin to gelatin at $1: 1$.

3.2. Morphology and Structure of the Complex Nanomicelles. The morphology of the complex micelles was observed by scanning electron microscopy. It can be seen from Figure 2(a) that the complex micelles exhibited a special spindle shape. Micelles were generally $30-90 \mathrm{~nm}$ in width and varied from 40 to $130 \mathrm{~nm}$ in length. The sericin micelles exhibited nearspherical morphology and had diameters of 20 to $70 \mathrm{~nm}$ in Figure 2(b). No images were acquired for gelatin micelles because of their high hydrophilicity.

Figure 3 was the image acquired by atomic force microscopy for the complex micelles. From this figure we can see that the complex micelles were spindle-shaped, with a width about $25-80 \mathrm{~nm}$ and length about $50-150 \mathrm{~nm}$. Figure 4 showed the high-resolution observation result for the single spindle complex micelles by field emission transmission electron microscopy. It can be seen that the complex nanomicelle was fusiform and the tip of the micelle had an opening. The complex nanomicelles exhibited a core-shell structure. The core is larger and the shell is relatively thinner and had a potential application for the pulmonary delivery system. 


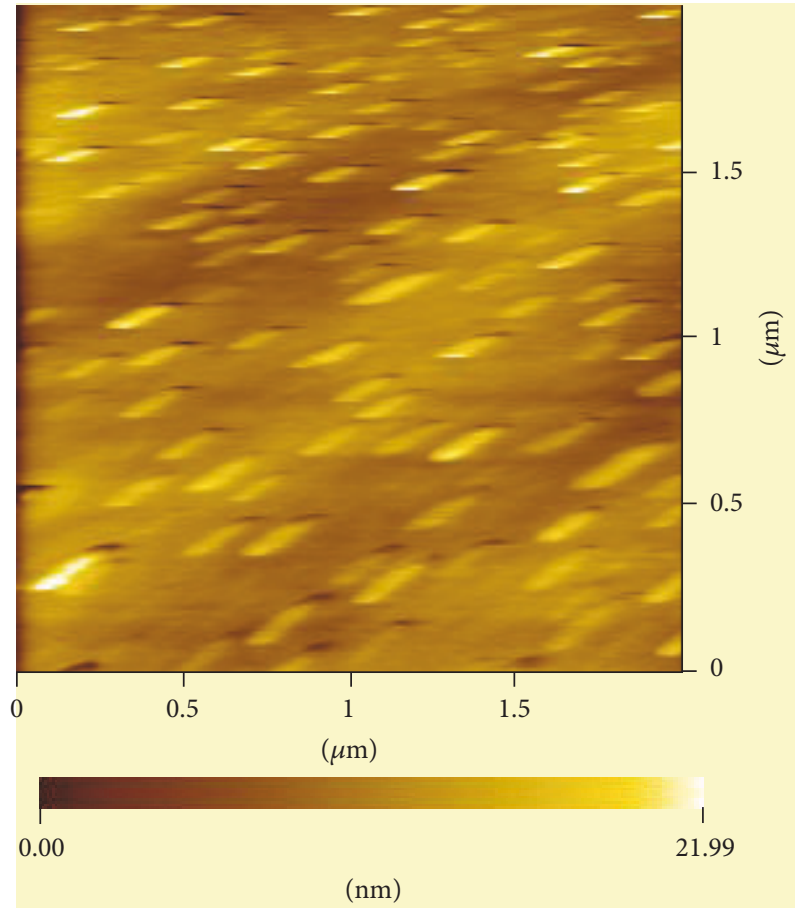

(a)

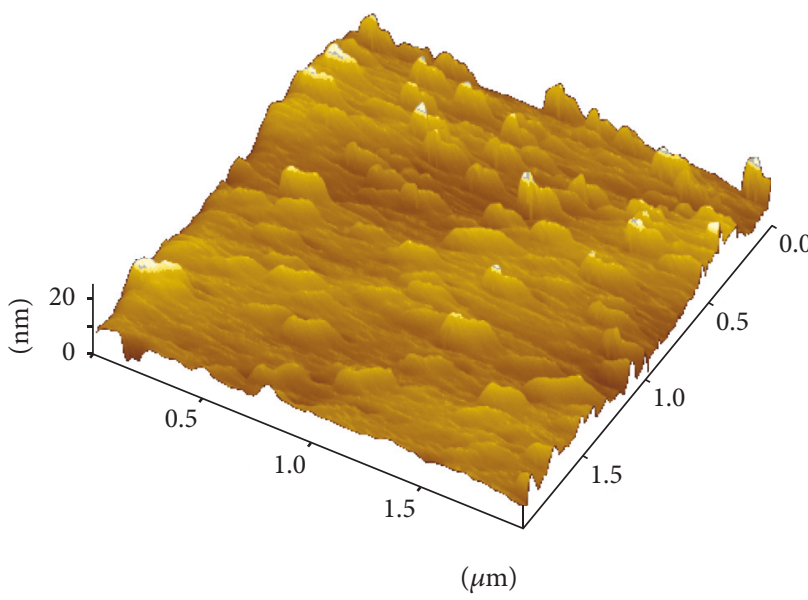

(b)

FIGURE 3: AFM images of the sericin/gelatin nanomicelles.

TABLE 1: Molecular weight of the sericin and type A gelatin component.

\begin{tabular}{lccccc}
\hline & $M_{n}$ & $M_{w}$ & $M_{z}$ & $M_{p}$ & Polydisperity \\
\hline Sericin & 4208 & 5789 & 3244 & 2845 & 1.376 \\
Type A gelatin & 78864 & 128664 & 102915 & 85655 & 1.631 \\
\hline
\end{tabular}

Note. $M_{n}$ represents number average molecular weight, $M_{w}$ represents average molecular weight, $M_{z}$ represents $z$-average molecular weight, and $M_{p}$ represents peak molecular weight.

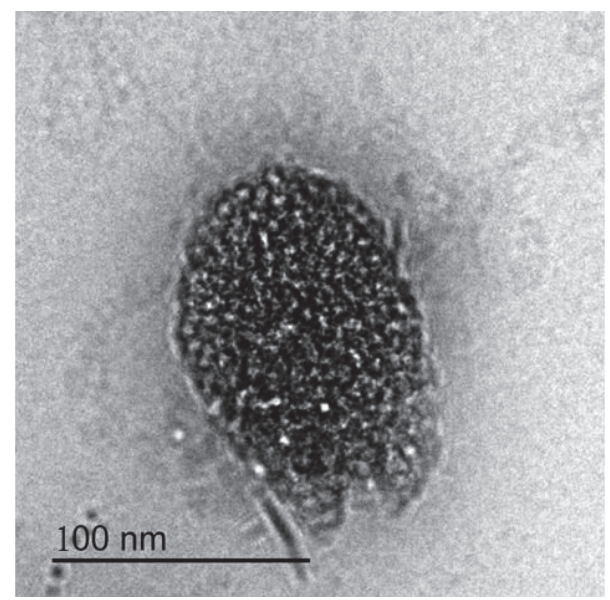

FIGURE 4: TEM images of the single sericin/gelatin nanomicelles.

The molecular weight of the sericin and type A gelatin used was determined by gel permeation chromatography. The results were shown in Table 1 . Sericin has an average molecular weight of $5789 \mathrm{Da}$ and the polydispersity was 1.376 .
Type A gelatin has an average molecular weight of $78864 \mathrm{Da}$ and the polydispersity was 1.631 . The results showed that the distribution range for molecular weight of sericin and type A gelatin was relatively narrow. The molecular weights for these two proteins were large enough to acquire the primitive assembly capacity.

3.3. Zeta-Potential of the Complex Nanomicelles. The values of zeta-potential for complex micelles at different $\mathrm{pH}$ were measured by using a Malvern particle size analyzer. The results were shown in Figure 5. It can be found that the zeta-potential of the micelles decreased from $-40.1 \mathrm{mV}$ to $-54.37 \mathrm{mV}$ when the $\mathrm{pH}$ of the solution system increased from 6.5 to 11.5. This indicated that the complex micelles system was more stable, and it became more stable with the decreasing value of $\mathrm{pH}$.

Figure 6 showed the variations of zeta-potential value of the composite micelles at the range of $30-70^{\circ} \mathrm{C}$. It can be seen that the value of the zeta-potential of the micelles solution system increased gradually from $-42.25 \mathrm{mV}$ to $-38.6 \mathrm{mV}$ when the temperature increased from $30^{\circ} \mathrm{C}$ to $70^{\circ} \mathrm{C}$. The result demonstrated that the micelles solutions system exhibited relatively high stability in high temperature. 

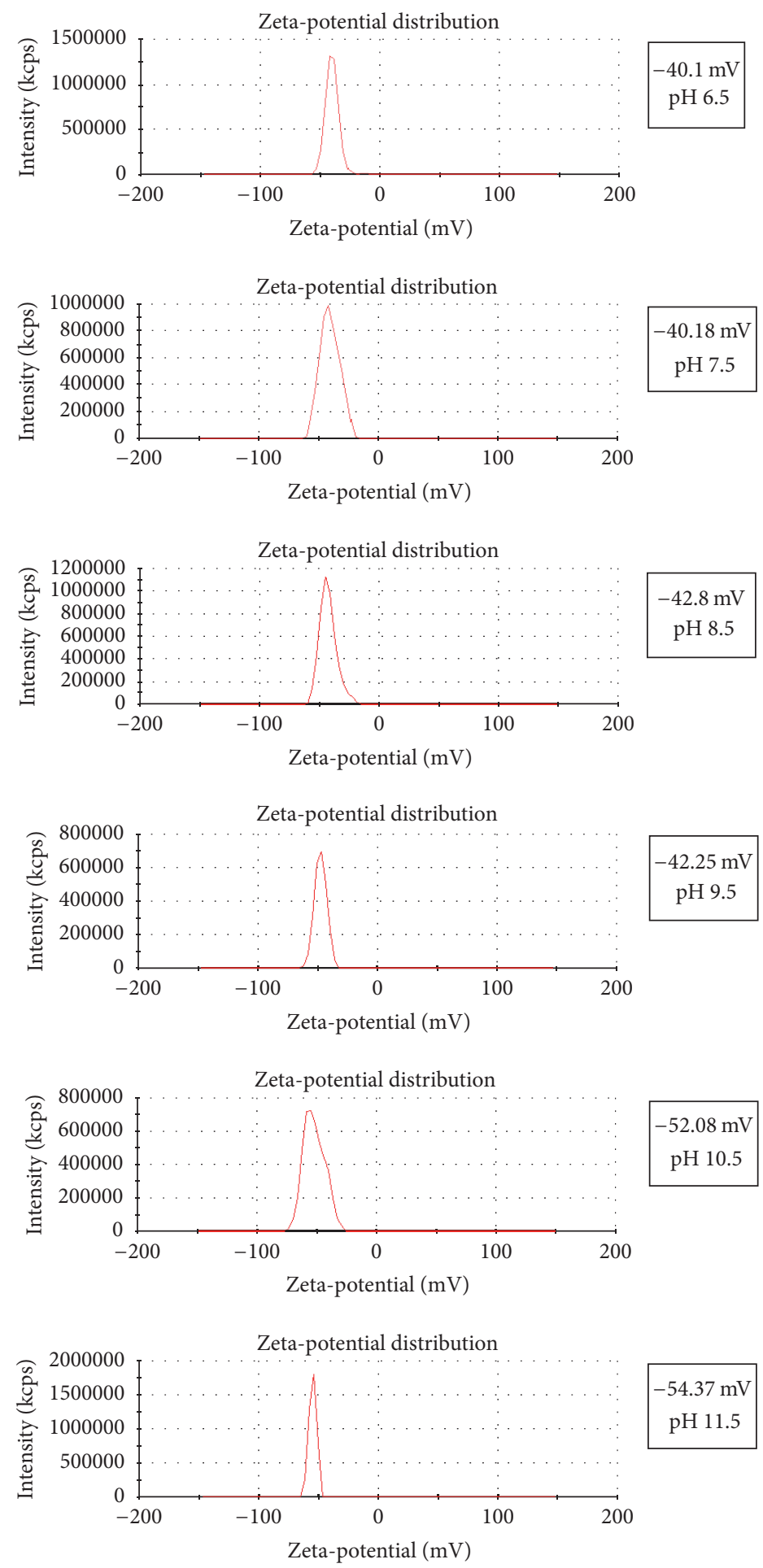

FIGURE 5: Zeta-potential of the complex micelles in different $\mathrm{pH}$.

3.4. Thermal Performance of the Complex Nanomicelles. The DSC curves of the complex nanomicelles including assembled and unassembled micelles were shown in Figure 7. Peaks 1-4 appeared in the curve of assembled micelles and peaks 5-7 appeared in the curve of unassembled micelles.

In the curve of unassembled micelles the wide heat absorption peak P1 $\left(50 \sim 170^{\circ} \mathrm{C}\right)$ was related to the phase transition of the hydrated sericin/gelatin crystal. The absorption peak P2 $\left(252^{\circ} \mathrm{C}\right)$ corresponded to the cleavage of sericin/gelatin crystal. Peak P3 $\left(283^{\circ} \mathrm{C}\right)$ was related to the cleavage of salt bonds, hydrogen bonds, and van der Waals forces in unassembled protein. Peak $\mathrm{P} 4\left(321^{\circ} \mathrm{C}\right)$ was related to the liquefaction and breakdown of sericin and gelatin peptide chains. 

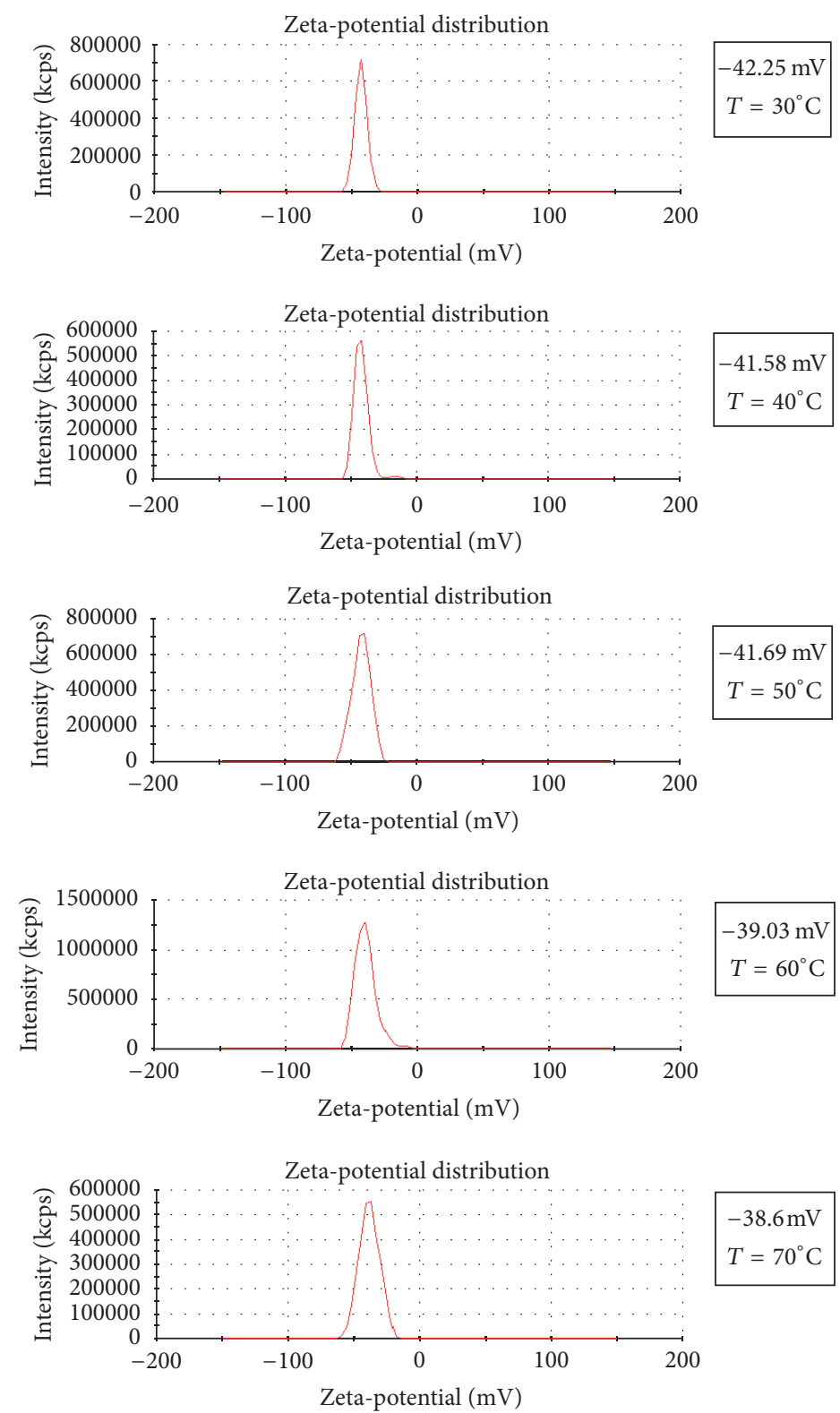

FIGURE 6: Zeta-potential of the complex micelles in different temperature.

In the curve of assembled micelles, the wide heat absorption P1 $\left(50 \sim 170^{\circ} \mathrm{C}\right)$ split into the two absorption peaks P5 $\left(78^{\circ} \mathrm{C}\right)$ and $\mathrm{P} 6\left(127^{\circ} \mathrm{C}\right)$. This indicated that the structure of the hydrated sericin/gelatin crystal had changed greatly after having been assembled. The peaks of P2, P3, and P4 disappeared and evolved into a higher temperature absorption peak P7 $\left(330^{\circ} \mathrm{C}\right)$. This demonstrated that the peptide chains rearranged and the micelles structure changed significantly powered by the salt bonds, hydrogen bonds, van der Waals forces, and hydrophobic interactions. The assembling effect improved thermal performance of the micelles remarkably.

3.5. Chemical Bonds Variations. Fourier infrared spectrometer analysis was conducted to investigate the chemical bonds variations in Figure 8. A new absorption band appeared at $964 \mathrm{~cm}^{-1}$ after assembling. The absorption in this area was related to the extra vibration of the $=\mathrm{C}-\mathrm{H}$ bond at conjugated double bond caused by assembling effect in phenylalanine, tryptophan, and tyrosine.

3.6. Stability of the Complex Nanomicelles. Complex micelles solutions $(0.5 \%)$ were diluted 1 time, 10 times, 50 times, and 200 times by deionized water. Their particle size and polydispersity index were measured by Malvern laser particle size analyzer. The results were shown in Figure 9. It can be seen that the particle size ranged from 83 to $112 \mathrm{~nm}$, and the value of polydispersity ranged from 0.518 to 0.632 . This indicated that the complex nanomicelles had better antidilution property. 


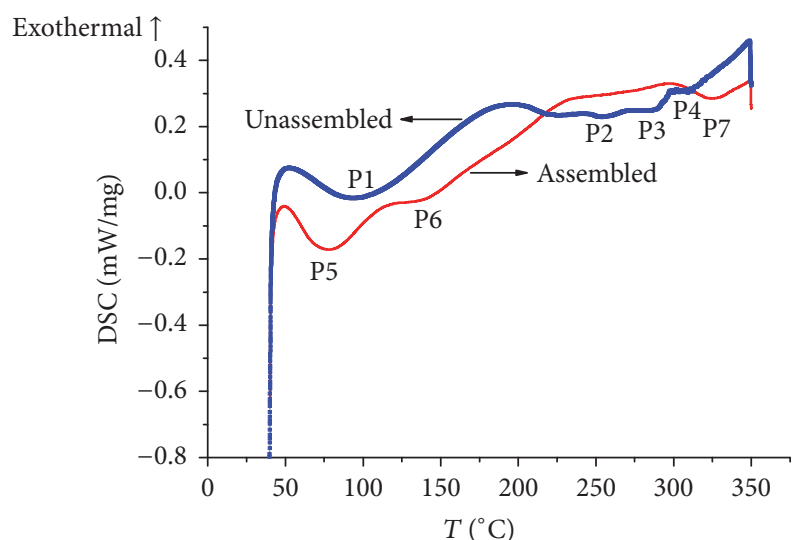

FIGURE 7: DSC thermograms of the sericin/gelatin complex micelles assembled and unassembled.

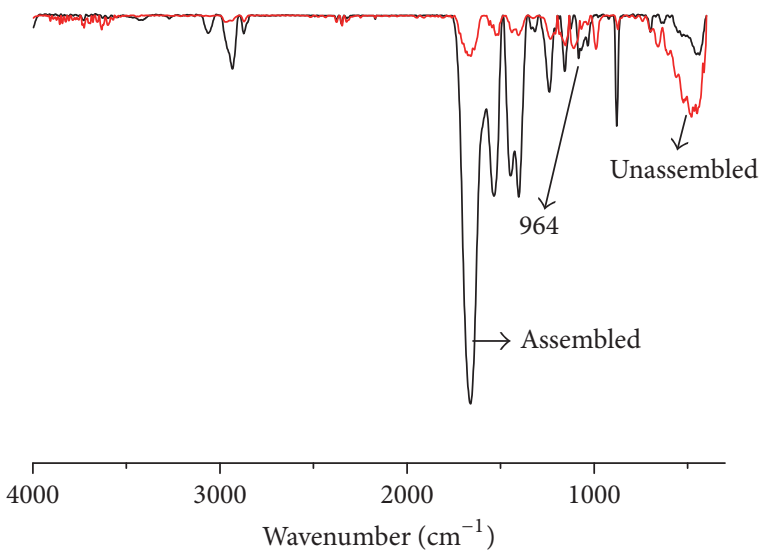

FIGURE 8: FT-IR spectra of the sericin/gelatin complex micelles assembled and unassembled.

The complex micelles were stored at room temperature for 40 days. Their particle size and polydispersity index were measured every 10 days. The results were shown in Figure 10. The results showed that the particle size of the complex nanomicelles ranged from 82 to $108 \mathrm{~nm}$ and the value of polydispersity ranged from of 0.505 to 0.645 . It demonstrated that the complex nanomicelles had better storage stability.

\section{Conclusions}

Complex micelles were prepared by sericin $\left(M_{w}=5789\right)$ and type A gelatin $\left(M_{w}=128664\right)$. The reaction conditions were as follows: mass ratio of sericin to gelatin was $1: 1$, protein solution concentration was $1.5 \%$, assembling temperature was $35^{\circ} \mathrm{C}$, and the assembling time was 18 hours. Then the complex micelles were fixed by glutaraldehyde at $25^{\circ} \mathrm{C}$ for 12 hours. Experiment results showed that the sericin and gelatin can self-assemble into nanospindle micelles in solution. The width of complex sericin/gelatin micelles was $30-90 \mathrm{~nm}$ and the length was $30-150 \mathrm{~nm}$. The solution of the sericin/gelatin micelles had a high zeta-potential, and the value increased from $-40.1 \mathrm{mV}$ to $-54.37 \mathrm{mV}$ in the $\mathrm{pH}$ range of $6.5-11.5$ and decreased from $-42.25 \mathrm{mV}$ to $-38.6 \mathrm{mV}$ at the

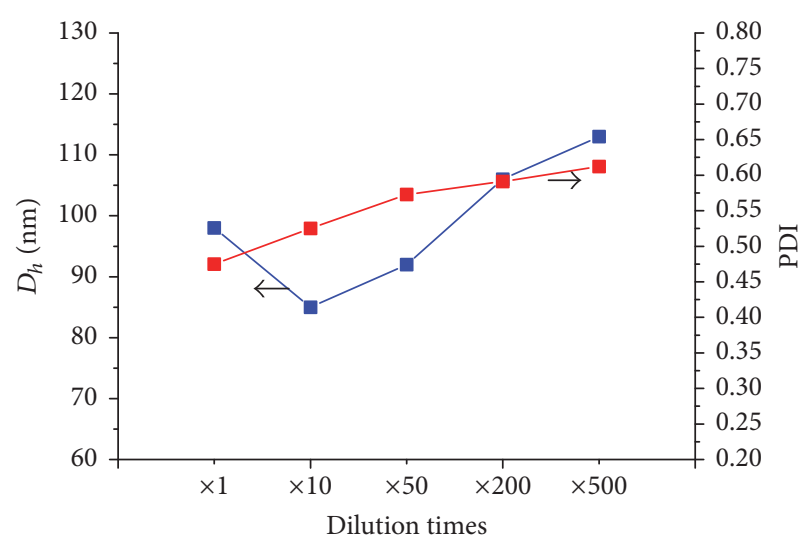

FIgURe 9: Particle size and polydispersity index of the complex micelles at different dilution times. The left arrow refers the blue line to $D_{h}$, and the right arrow refers the red line to the PDI.

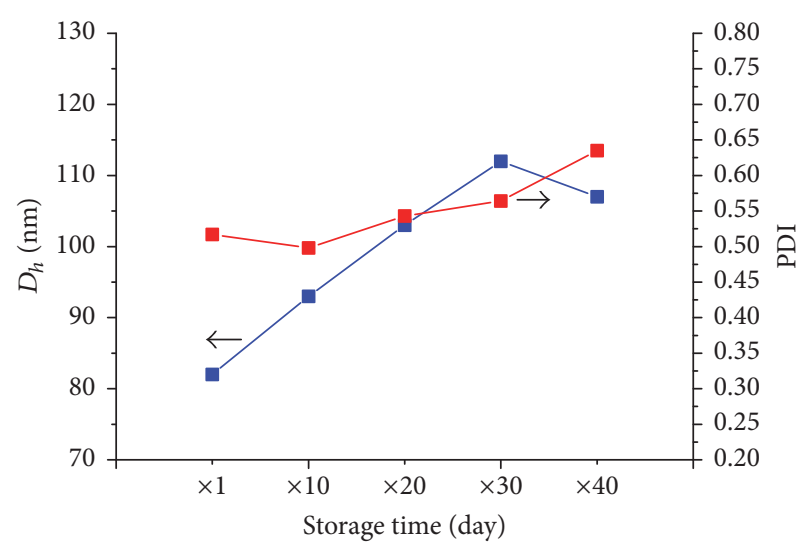

FIGURe 10: Particle size and polydispersity index of the complex micelles at different storage times. The left arrow refers the blue line to $D_{h}$ and the right arrow refers the red line to the PDI.

temperature of $30-70^{\circ} \mathrm{C}$. The complex sericin/gelatin micelles had stable chemical structure, good thermal performance, dilution stability, and storage stability.

\section{Conflicts of Interest}

The authors declare that there are no conflicts of interest regarding the publication of this paper.

\section{Acknowledgments}

This work was financially supported by Henan Province Universities Key Research Project (17A540003) and National Natural Science Foundation of China (NSFC) (U140454).

\section{References}

[1] F. S. Bates and G. H. Fredrickson, "Block copolymer thermodynamics: theory and experiment," Annual Review of Physical Chemistry, vol. 41, no. 1, pp. 525-557, 1990. 
[2] I. Hamley, The physics of block copolymers, Oxford University Press, Oxford, UK, 1998.

[3] F. S. Bates and G. H. Fredrickson, "Block copolymers-designer soft materials," Physics Today, vol. 52, no. 2, pp. 32-38, 1999.

[4] D. A. Hajduk, R.-M. Ho, M. A. Hillmyer, F. S. Bates, and K. Almdal, "Transition mechanisms for complex ordered phases in block copolymer melts," The Journal of Physical Chemistry B, vol. 102, no. 8, pp. 1356-1363, 1998.

[5] V. Castelletto and I. W. Hamley, "Morphologies of block copolymer melts," Current Opinion in Solid State \& Materials Science, vol. 8, no. 6, pp. 426-438, 2004.

[6] R. J. Spontak and P. Alexandridis, "Advances in self-ordering macromolecules and nanostructure design," Current Opinion in Colloid \& Interface Science, vol. 4, no. 2, pp. 140-146, 1999.

[7] J. Zhao, B. Majumdar, M. F. Schulz et al., "Phase behavior of pure diblocks and binary diblock blends of poly(ethylene)poly(ethylethylene)," Macromolecules, vol. 29, no. 4, pp. 1204$1215,1996$.

[8] I. W. Hamley, M. D. Gehlsen, A. K. Khandpur et al., "Complex layered phases in asymmetric diblock copolymers," Journal de Physique II, vol. 4, no. 12, pp. 2161-2186, 1994.

[9] S. B. Darling, "Directing the self-assembly of block copolymers," Progress in Polymer Science, vol. 32, no. 10, pp. 1152-1204, 2007.

[10] Y. Mogi, H. Kotsuji, Y. Kaneko, K. Mori, Y. Matsushita, and I. Noda, "Preparation and morphology of triblock copolymers of the ABC type," Macromolecules, vol. 25, no. 20, pp. 5408-5411, 1992.

[11] R. B. Grubbs, "Hybrid metal-polymer composites from functional block copolymers," Journal of Polymer Science Part A: Polymer Chemistry, vol. 43, no. 19, pp. 4323-4336, 2005.

[12] S. K. Kumar and R. Krishnamoorti, "Nanocomposites: structure, phase behavior, and properties," Annual Review of Chemical and Biomolecular Engineering, vol. 1, pp. 37-58, 2010.

[13] B. J. Kim, J. J. Chiu, G.-R. Yi, D. J. Pine, and E. J. Kramer, "Nanoparticle-induced phase transitions in diblock-copolymer films," Advanced Materials, vol. 17, no. 21, pp. 2618-2622, 2005.

[14] W. Zhang, L. Shi, Y. An et al., "Dsorption of P4VP Unimers into PS-b-PAA Micelles in Ethanol Due to Hydrogen Bonding," Macromolecules, vol. 37, no. 8, pp. 2924-2929, 2004.

[15] J. Seo, J. L. Lutkenhaus, J. Kim, P. T. Hammond, and K. Char, "Development of surface morphology in multilayered films prepared by layer-by-layer deposition using poly(acrylic acid) and hydrophobically modified poly(ethylene oxide)," Macromolecules, vol. 40, no. 11, pp. 4028-4036, 2007.

[16] B.-S. Kim, S. W. Park, and P. T. Hammond, "Hydrogen-bonding layer-by-layer-assembled biodegradable polymeric micelles as drug delivery vehicles from surfaces," ACS Nano, vol. 2, no. 2, pp. 386-392, 2008.

[17] S. C. Lee and H. J. Lee, "pH-controlled, polymer-mediated assembly of polymer micelle nanoparticles," Langmuir, vol. 23, no. 2, pp. 488-495, 2007.

[18] B. Atmaja, J. N. Cha, A. Marshall, and C. W. Frank, "Supramolecular assembly of block copolypeptides with semiconductor nanocrystals," Langmuir, vol. 25, no. 2, pp. 707-715, 2009.

[19] S.-W. Kuo, H.-F. Lee, C.-F. Huang, C.-J. Huang, and F.-C. Chang, "Synthesis and self-assembly of helical polypeptide-random coil amphiphilic diblock copolymer," Journal of Polymer Science Part A: Polymer Chemistry, vol. 46, no. 9, pp. 3108-3119, 2008.

[20] L. J. Zhang, Y. Z. Long, Z. J. Chen, and M. X. Wan, “The effect of hydrogen bonding on self-assembled polyaniline nanostructures," Advanced Functional Materials, vol. 14, no. 7, pp. 693-698, 2004.
[21] Y. N. Xia, J. A. Rogers, K. E. Paul, and G. M. Whitesides, "Unconventional methods for fabricating and patterning nanostructures," Chemical Reviews, vol. 99, no. 7, pp. 1823-1848, 1999.

[22] R. J. Jackman, S. T. Brittain, A. Adams, M. G. Prentiss, and G. M. Whitesides, "Design and fabrication of topologically complex, three-dimensional microstructures," Science, vol. 280, no. 5372, pp. 2089-2091, 1998.

[23] Y. Liu and R. Guo, "pH-dependent structures and properties of casein micelles," Biophysical Chemistry, vol. 136, no. 2-3, pp. 6773, 2008.

[24] X. Pan, S. Yu, P. Yao, and Z. Shao, "Self-assembly of $\beta$-casein and lysozyme," Journal of Colloid and Interface Science, vol. 316, no. 2, pp. 405-412, 2007.

[25] Y. Liu and R. Guo, "Aggregation properties of aqueous casein hydrolysate solutions at different $\mathrm{pH}$," International Dairy Journal, vol. 18, no. 10-11, pp. 1022-1027, 2008.

[26] J. Kanoujia, M. Singh, P. Singh, and S. A. Saraf, "Novel genipin crosslinked atorvastatin loaded sericin nanoparticles for their enhanced antihyperlipidemic activity," Materials Science and Engineering C: Materials for Biological Applications, vol. 69, pp. 967-976, 2016.

[27] S. Xiao-Zhou, W. Hong-Ru, and H. Mian, "Characterization of the casein/keratin self-assembly nanomicelles," Journal of Nanomaterials, vol. 2014, Article ID 183815, 7 pages, 2014.

[28] T. E. Mallouk, "Stretching the mold," Science, vol. 291, no. 5503, pp. 443-444, 2001.

[29] S. A. Johnson, P. J. Ollivier, and T. E. Mallouk, "Ordered mesoporous polymers of tunable pore size from colloidal silica templates," Science, vol. 283, no. 5404, pp. 963-965, 1999.

[30] D. Zhao, J. Feng, Q. Huo et al., "Triblock copolymer syntheses of mesoporous silica with periodic 50 to 300 angstrom pores," Science, vol. 279, no. 5350, pp. 548-552, 1998.

[31] D. L. Johnson, M. Polikandritou-Lambros, and T. B. Martonen, "Drug encapsulation and aerodynamic behavior of a lipid microtubule aerosol," Drug Delivery: Journal of Delivery and Targeting of Therapeutic Agents, vol. 3, no. 1, pp. 9-15, 1996.

[32] R. Dash, C. Acharya, P. C. Bindu, and S. C. Kundu, "Antioxidant potential of silk protein sericin against hydrogen peroxideinduced oxidative stress in skin fibroblasts," Journal of Biochemistry and Molecular Biology, vol. 41, no. 3, pp. 236-241, 2008.

[33] P. Aramwit, P. Towiwat, and T. Srichana, "Anti-inflammatory potential of silk sericin," Natural Product Communications (NPC), vol. 8, no. 4, pp. 501-504, 2013.

[34] M. Sano, Y. Tamada, K. Niwa, T. Morita, and G. Yoshino, "Sulfated sericin is a novel anticoagulant influencing the blood coagulation cascade," Journal of Biomaterials Science, Polymer Edition, vol. 20, no. 5-6, pp. 773-783, 2009.

[35] Y. Tamada, M. Sano, K. Niwa, T. Imai, and G. Yoshino, "Sulfation of silk sericin and anticoagulant activity of sulfated sericin," Journal of Biomaterials Science, Polymer Edition, vol. 15, no. 8, pp. 971-980, 2004.

[36] Y.-Q. Zhang, Y. Ma, Y.-Y. Xia, W.-D. Shen, J.-P. Mao, and R.-Y. Xue, "Silk sericin-insulin bioconjugates: synthesis, characterization and biological activity," Journal of Controlled Release, vol. 115, no. 3, pp. 307-315, 2006.

[37] Y.-Q. Zhang, M.-L. Tao, W.-D. Shen, J.-P. Mao, and Y.-H. Chen, "Synthesis of silk sericin peptides-L-asparaginase bioconjugates and their characterization," Journal of Chemical Technology and Biotechnology, vol. 81, no. 2, pp. 136-145, 2006.

[38] K. Ofokansi, G. Winter, G. Fricker, and C. Coester, "Matrixloaded biodegradable gelatin nanoparticles as new approach 
to improve drug loading and delivery," European Journal of Pharmaceutics and Biopharmaceutics, vol. 76, no. 1, pp. 1-9, 2010.

[39] Y.-W. Won, S.-M. Yoon, C. H. Sonn, K.-M. Lee, and Y.H. Kim, "Nano self-assembly of recombinant human gelatin conjugated with $\alpha$-tocopheryl succinate for Hsp90 inhibitor, 17AAG, delivery," ACS Nano, vol. 5, no. 5, pp. 3839-3848, 2011.

[40] A. Abbasi, M. Eslamian, D. Heyd, and D. Rousseau, "Controlled release of DSBP from genipin-crosslinked gelatin thin films," Pharmaceutical Development and Technology, vol. 13, no. 6, pp. 549-557, 2008.

[41] R. T. Andrews and C. A. Binkert, "Relative rates of blood flow reduction during transcatheter arterial embolization with trisacryl gelatin microspheres or polyvinyl alcohol: Quantitative comparison in a swine model," Journal of Vascular and Interventional Radiology, vol. 14, no. 10, pp. 1311-1316, 2003.

[42] C. C. Goodno, H. E. Swaisgood, and G. L. Catignani, "A fluorimetric assay for available lysine in proteins," Analytical Biochemistry, vol. 115, no. 1, pp. 203-211, 1981. 

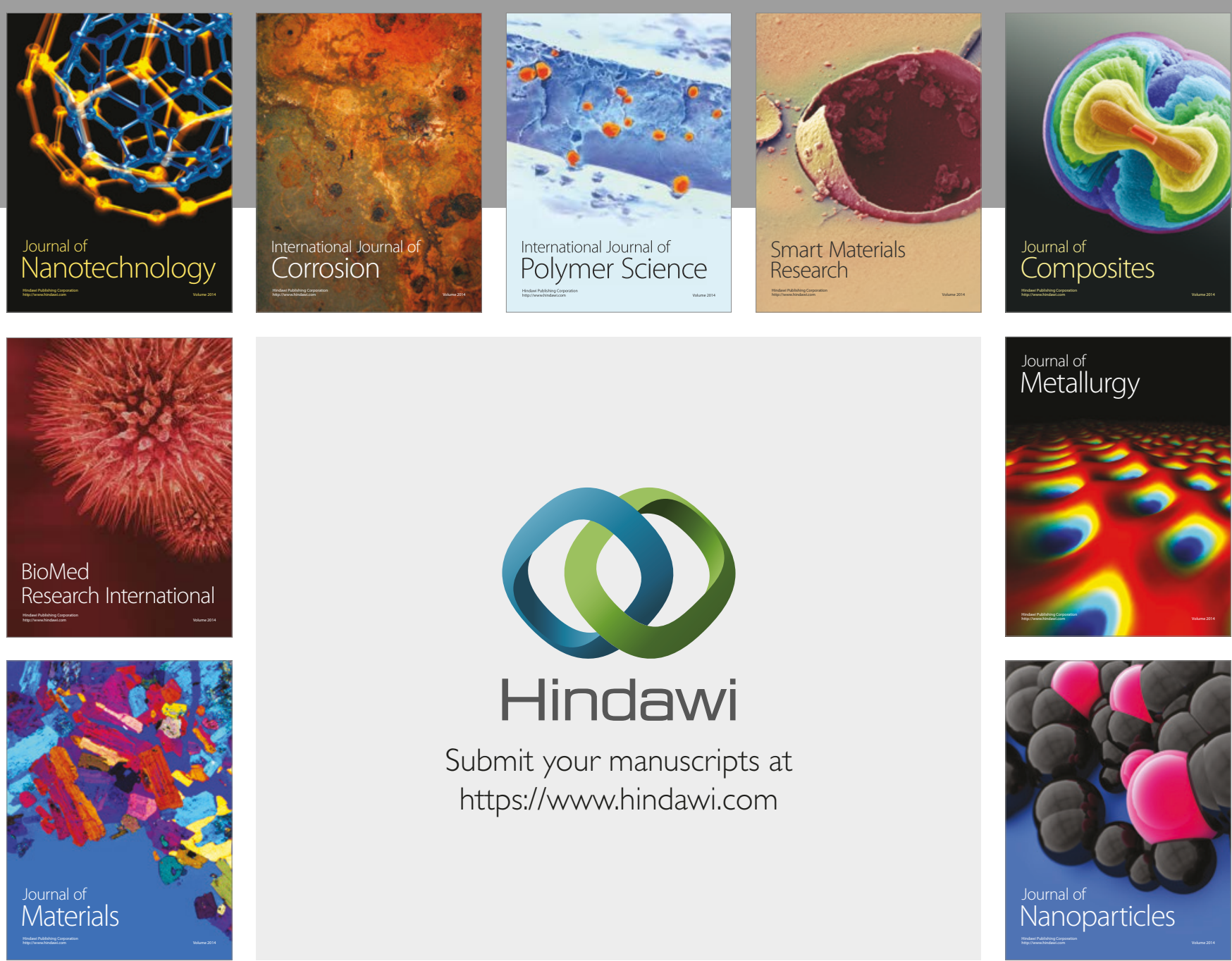

\section{Hindawi}

Submit your manuscripts at

https://www.hindawi.com
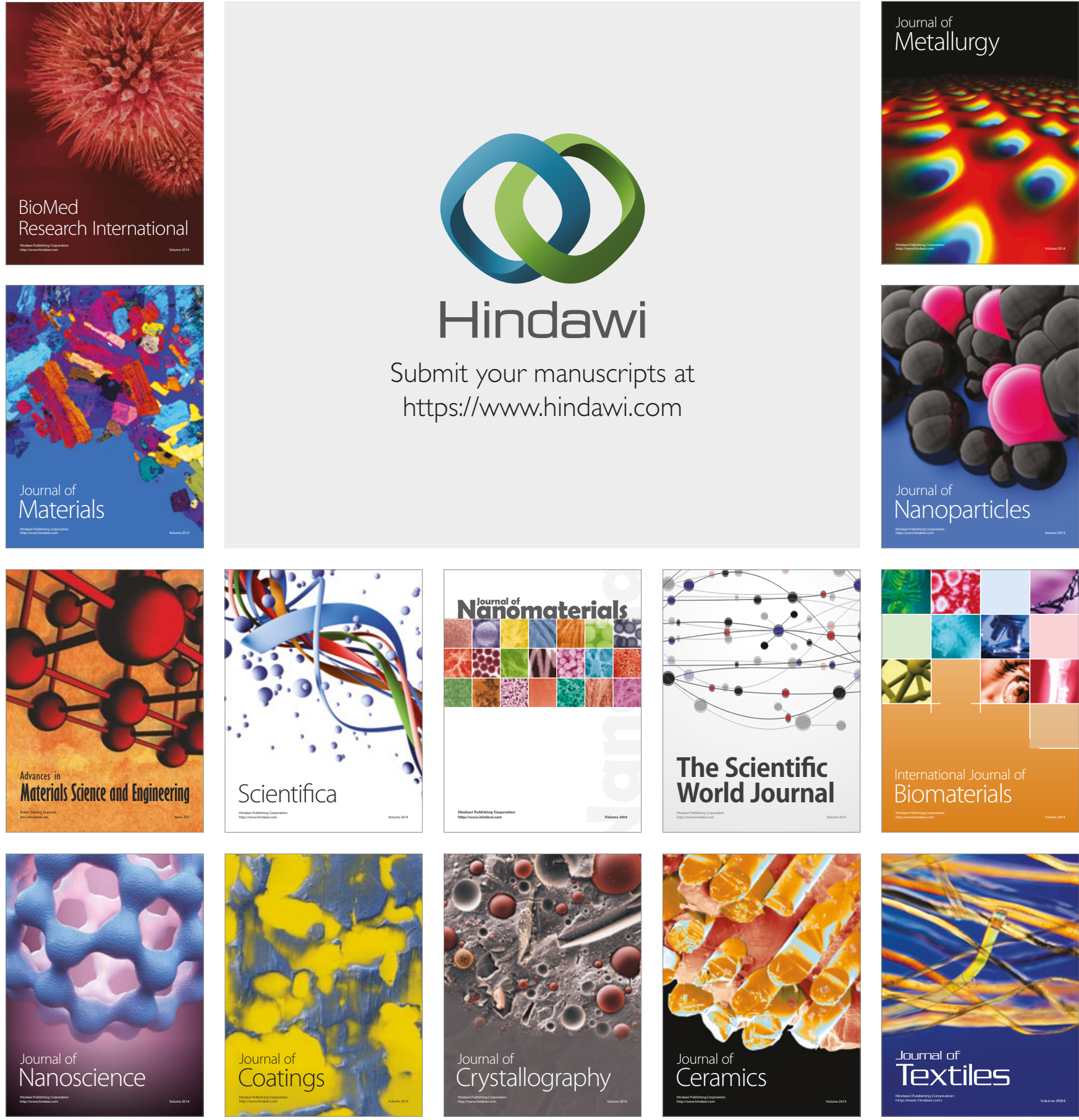

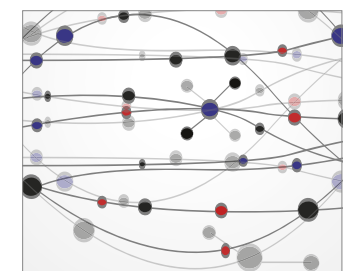

The Scientific World Journal
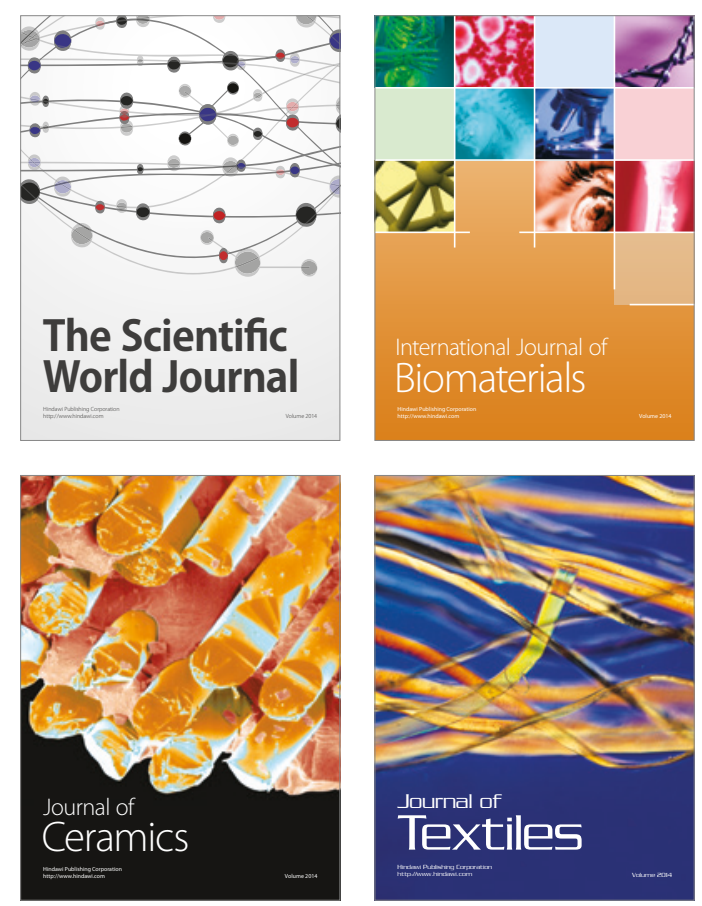